\title{
Empirical Test of the Relationship between the Performance and the Concentration on Stocks of Chinese Security Investment Funds
}

\author{
Wei $\mathrm{Hu}$ \\ School of Management, Fudan University, Shanghai 200433, China \\ Tel: 86-21-2501-1069 E-mail: whu@fudan.edu.cn
}

\begin{abstract}
The concentration on stocks of security investment funds reflects fund managers' utilization degree of the inefficiency of market, so certain relationship exists between the performance of funds and the concentration on stocks. By analyzing practical data of Chinese stock investment funds, the relationship between the performance and the concentration on stocks is tested in the article, and the result shows that properly high concentration on stocks can help to enhance the risk adjusted return of funds, but too high concentration on stocks will influence the timing selection of funds. And in the test, some different results are discovered.
\end{abstract}

Keywords: Fund, Performance, Concentration on stocks

\section{Introduction}

The security investment funds, as one of most important institutional investors in the security market, are always concerned by the market participators. Their investment performances, performance sources and risks are key factors which are concerned by most investors and supervisors. At the same time, in theory, whether the actively managed funds can continually acquire excess incomes is one important factor to test the efficiency of the market, so it is very important and meaningful to study the performance of funds both in theory and in practice.

In fact, in 1960s, based on the theory of CAPM, Treynor (Treynor, 1965, P.131-136), Sharpe (Sharpe, 1966, P.119-138) and Jensen (Jensen M, 1968, P.389-416) took the risk adjusted return as the performance evaluation index of funds to replace originally single index of yield, and these indexes about the risk adjusted return including the three-factor model proposed by Fama \& French (Treynor, 1966, P.131-136) based on that became into classic performance evaluation indexes of funds, which have been applied widely up to now. In addition, in Treynor \& Mazuy (Treynor, 1966, P.131-136)'s model, the source of the fund performance were divided into the stock selection ability and the timing selection ability of funds, and Henriksson \& Merton (Henriksson, 1981, P.513-533) also put forward similar model subsequently, and these two selection abilities were adopted by many researches. And the research about the performance of funds had been the durative hot spot from that time.

In China, the industry of funds just started from 1990s, and it have been developed quickly in recent years, and with the accumulation of data, the theory and empirical researches taking domestic funds as the objects are more and more. For example, in 2001, Wang Cong (Wang, 2001, P.31-38) early introduced and evaluated the foreign fund evaluation model in detail, and at the same year, Shen Weitao and Huang Xingluan (Shen, 2001, P.22-30) applied the model which had been widely used in the foreign fund performance to empirically study the performance of Chinese security investment funds with short history. After that, $\mathrm{Wu}$ Chongfeng et al (Wu, 2002, P.128-133) also completely reviewed the theories of west security investment fund performance evaluation, and Zhang Xin and Du Shuming (Zhang, 2002, P.1-22) comprehensively measured the performances of domestic funds by the classic performance evaluation indexes of funds, and discussed the timing selection ability of funds, the risk diversification degree and the asset allocation.

Except that taking the risk adjusted return as the measurement index to review the performance of fund, the concentration on stocks is also used to directly judge the asset management ability of funds, for example, in 1997, according to the character of the concentration on stocks of funds, Daniel (Daniel Kent, 1997, P.1035-1058) studied whether the funds could select the stocks with positive excess incomes in the stocks with same characters, and in 2006, Hu Wei and Zhang Ming (Hu, 2006, P.26-32) used similar method to study the stock selection ability of domestic funds.

In fact, to study the concentration on stocks of funds, except for establishing the performance evaluation index which is different with the classic model, the relationship between the performance of funds and the concentration on stocks can be also studied. Marcin et al (Marcin, 2005, P.1983-2011) put forward that if the fund managers had some advantages in some industries, the investment combinations managed by them might centralize in a few industries, not in every industry, and they empirically tested the common actively managed funds of US from 1984 to 1999, and the result indicated that when the risk and the style difference are controlled, the funds centralized in a few industries would obtain better performance. In the research about the US mutual Funds from 1984 to 2002, Hany \& David (Hany, 2005, 
P.481-495) proved above opinion, and they found that the funds with good concentration on stocks had good performance, and after considering the charges and other characters, they thought the performance of funds was positively correlative with the stock holding amount. Many domestic scholars also developed the research about this aspect, and Liang Bin (Liang, 2007, P.7-11) reviewed the relationship between the performance and the concentration on stocks of Chinese close-ended funds in 2007, and the result showed that the performance of the funds with centralized stock holding were better than the funds with dispersive stock holding, and Xie Hongtao \& Zhou Shaofu (Xie, 2008, P.52-56) studied the data of Chinese open-ended funds from 2003 to 2007, and found that the asset allocation concentration in the selection of stocks could bring excess incomes for funds, and too high industrial concentration would bring losses for funds.

Above research results are not consistent completely, but these opinions are very meaningful, that is to say, as the fund managers who are the experts managing the investment portfolios, whether they should trust that they have the ability to win in the market and should focus in their familiar domains to look for proper investment opportunities, or they should believe traditional theory about the investment portfolios, i.e. reducing the risks by the diversification investments? Based on above research ideas and the data of domestic stock funds, the relationship between the performance of funds and the concentration on stocks is discussed as follows.

\section{Theoretical model}

According to traditional investment portfolio theory, the diversification investment can reduce the risks, so the fund managers, as the investment expert, should invest capitals in more stocks as possible to acquire same benefits when the risks are possibly low. However, a premise must be considered, i.e. the market should be efficient. But the market is often inefficient, and the inefficiency of the market is just one important reason for the existence of funds. Just thinking, if the market is efficient and the pricing of all securities are reasonable, so investors can directly invest in stocks, and why they let experts to manage their capitals? Therefore, for the funds investors, the fund managers should try to look for the mispriced stocks in the market to obtain the premium over the average return in the market (except for the index funds), but fund managers have only limited energies and resources, and facing thousands of stocks in the market, they can not pay attention to each one, so the reasonable method is to pay attention to part of stocks or industries which they are familiar. Therefore, the first deduction can be obtained.

The funds with high stock holding or industrial concentration on stocks should have better performances.

Though the market is not completely effective, but the function of the diversification investment to reduce the risks still exists. Except for the returns, the risks should also be considered more when we evaluate the performances of funds, for example, whether they take the risk adjusted returns as the evaluation index of fund performance. Therefore, when the concentration on stocks of funds is too high, the risks will increase and the performances will be influenced. So the second deduction which is similar with Hany \& David's (Hany, 2005, P.481-495) can be obtained.

The performance of the funds with too high stock holding or industrial concentration on stocks will descend.

Next, the data of domestic stock funds will be used to test above two deductions.

\subsection{Index of fund performance}

There are many indexes to reflect the performances of funds.

(1) The excess yield (y)

$$
y=R_{\text {Fund }}-R_{\text {Mkt }} \times \text { Ratio }
$$

Where, $R_{\text {Fund }}$ and $R_{M k t}$ respectively are the net yield of the fund and the market index yield, and Ratio is the stock holding proportion of this fund. This index directly reflects the excess return of the stock part in the fund in the whole stock market, and the risks are not considered.

(2) Jensen index (jensen)

$$
\text { jensen }=\left(R_{\text {Fund }}-R_{f}\right)-\beta \times\left(R_{\text {Mkt }}-R_{f}\right)
$$

Where, $R_{f}$ is the risk free rate, $\beta$ is the value of Beta obtained according to the model of CAPM, and it reflects the system risk. This index is a risk adjusted return index comprehensively considering the incomes and risks, and it is the usual performance evaluation index of funds.

(3) Net asset volatility ( $\mathrm{vol})$

$$
v o l=\sqrt{\frac{1}{n-1} \sum_{i=1}^{n}\left(R_{i}-\bar{R}\right)^{2}}
$$

Where, $R_{i}$ is the return of net asset of the fund at the $i^{\prime}$ th term, and $\bar{R}$ is the average value of $n$ terms. This index is not a performance evaluation in fact, and it is just a risk index reflecting the instability of the return. It can be used to show 
the risks of the funds with different concentrations on stocks.

(4) Treynor \& Mazuy (Treynor, 1966, P.131-136)'s stock selection ability and timing selection ability (ss and tim)

$$
R_{\text {Fund }}-R_{f}=s s+\beta \cdot\left(R_{M k t}-R_{f}\right)+\operatorname{tim} \cdot\left(R_{M k t}-R_{f}\right)^{2}+\varepsilon
$$

This model can decompose the excess return of the fund, and ss and tim can be obtained by the regression, and they respectively denote fund managers' abilities to select stock and select the market opportunity.

\subsection{Index of concentration on stocks}

In different researches, there are many indexes to denote the concentration on stocks of funds, for example, Marcin et al (Marcin, 2005, P.1983-2011) established a index to measure the industrial concentration on stocks by computing the difference between the proportion of stocks in each industry in the stock portfolio and the proportion that the industry in the market combination. Hany \& David (Hany, 2005, P.481-495) directly used the amount of stock hold by the fund to measure the concentration. And Travis \& Yan (Travis, 2008, P.27-49) used same index with Marcin et al (Marcin, 2005, P.1983-2011) in the stock concentration degree from the industrial concentration, and called it as the Herfindahl index, and obtained same result. Liang Bin et al (Liang, 2007, P.7-11) used the Gini coefficient and Herfindahl index, and Xie Hongtao \& Zhou Shaofu (Xie, 2008, P.52-56) used the index which is similar with Marcin's. The Herfindahl index used by Liang Bin et al was an index to measure the market concentration degree of certain industry in the market. This index can better reflect the stock holding concentration of funds, so it is used to denote the stock holding concentration of funds $\left(H_{s t k}\right)$ and the concentration of industry $\left(H_{i n d}\right)$.

$$
\begin{aligned}
& H_{\text {stk }}=\sum_{i} w_{\text {stk }, i}^{2} \\
& H_{\text {ind }}=\sum_{i} w_{\text {ind }, i}^{2}
\end{aligned}
$$

Where, $w_{s t k, I}$ and $w_{\text {ind, } i}$ respectively denote the market value proportions of the $i^{\prime}$ th stock and the $j^{\prime}$ th industry holding stocks in all stocks. From (5) and (6), $H$ is bigger, it denotes that stock invested by the fund is more centralized in individual stock or individual industry, and when $H$ equals to 1 , the fund completely invests in certain one stock or one industry. Therefore, $H$ is bigger, and the concentration degree is higher.

\subsection{Regression model}

Based on the practical data of domestic stock investment funds, the regression model is used to test the relationship between the performance and the concentration on stocks. According to former two deductions, the following regression models are used in the research.

$$
\begin{aligned}
& \operatorname{Per}_{i, t}=\alpha+\beta \cdot H_{i, t}+\gamma_{1} \cdot D_{1, t}+\gamma_{2} \cdot D_{2, t}+\gamma_{3} \cdot D_{3, t}+\varepsilon_{i, t} \\
& \operatorname{Per}_{i, t}=\alpha+\beta_{1} \cdot H_{i, t}+\beta_{2} \cdot H_{i, t}{ }^{2}+\gamma_{1} \cdot D_{1, t}+\gamma_{2} \cdot D_{2, t}+\gamma_{3} \cdot D_{3, t}+\varepsilon_{i, t}
\end{aligned}
$$

Where, $\mathrm{Per}_{i, t}$ denotes the performance of the i'th fund in the year of $t$, i.e. those indexes from the formula (1) to the formula (4). $H_{i, t}$ denotes the stock holding concentration or the industry concentration of the i'th fund in the year of $t . \mathrm{D}_{1}$, $\mathrm{D}_{2}$ and $\mathrm{D}_{3}$ are dummy variables, and because the panel data from 2004 to 2007 are selected, and the data in each year are significantly different, so these three dummy variables are introduced to denote the years.

$D_{1, t}=\left\{\begin{array}{cc}1 & t=2005 \\ 0 & \text { else }\end{array} D_{2, t}=\left\{\begin{array}{cc}1 & t=2006 \\ 0 & \text { else }\end{array} D_{3, t}=\left\{\begin{array}{cc}1 & t=2007 \\ 0 & \text { else }\end{array}\right.\right.\right.$

$\alpha, \beta$ and $\gamma$ are parameters, and $\varepsilon$ is the residual error. According to the anticipation in above discussions, $\beta$ in (7) should be positive, and $\beta_{1}$ in (8) should be positive but $\beta_{2}$ in (8) should be negative (the instance that vol denotes the performance is not included).

\section{Data}

The data of Chinese stock funds from 2004 to 2007 are used to empirical test the index, and all data are picked up from the financial terminal of Wind. For each fund, one performance evaluation index in each year is computed, and the week data are used to compute the risk return index and the stock selection ability and the timing selection ability, and the data of the end of last year are used to compute the index of concentration degree.

Table 1 is the description statistics for the data used in the article.

From the average data of various funds, both the excess yield and the risk adjusted return all exceed zero, and comparing with the whole market, the funds have certain advantages, but there are large differences in different years. The risk indexes, the stock selections and the timing selections are also different in different years. The stock holding concentrations of fund and the industrial concentrations change little in different years. 


\section{Empirical result and analysis}

The regression results of the formula (7) and the formula (8) are seen in Table 2 and Table 3.

From Table 2, the regression coefficient of Jensen index to the concentration on stocks is significantly positive, which indicates that the risk adjust return of the fund with centralized stock holding is higher, and the regression coefficient of the volatility $(\mathrm{vol})$ to the concentration on stocks is significantly negative, which shows the fund with high stock holding concentration can better control the net asset volatility, and there is another possibility, i.e. the high risk adjusted return of these funds comes from the control of risk. In addition, though the regression coefficients of the timing selection and the stock selection to the concentration on stocks are positive, but they are not significant.

For the relationship between the performance of funds and the concentration on stocks, the regression coefficient of Jensen index to the industrial concentration is significantly positive, which reflects that the funds with high industrial concentration can acquire better performances, but being different with the regression to the concentration on stocks, the regression coefficient of the volatility to the industrial concentration is positive, but not significant, which indicates that the risk adjusted returns of these funds come from actual returns, not controlling risks. In addition, the regression coefficient of the stock selection to the industrial concentration is significantly positive, which shows that the funds which absorbed in certain industries have the ability to select the predominant stocks in the industry or predominant industries.

In the regression results of the fund performances to the concentration on stocks and its square item, the regression result of the timing selection index accords with the anticipation, i.e. the first-order item is positive, and the second-order item is negative, and both of them are significant. That indicates that the funds with proper concentration on stocks have strong timing selection ability, and the funds with higher or lower concentration possesses weak timing selection ability. The regression coefficients of other performance indexes to the concentration on stocks and its square item are not significant, which doesn't support above deductions.

In the regression results of the performance to the industrial holding concentration and its square item, only the regression result of the stock selection index can narrowly accord with the anticipation, i.e. the first-order item is positive, and it is significant under $10 \%$, and the second-order item is negative, but not significant. That shows the funds with proper industrial concentration have better stock selection ability than other funds with higher or lower industrial concentration. But the regression result of the timing selection index is opposite with the anticipation, i.e. the first-order item is negative, and the second-order item is positive, and both of them are significant. That indicates the funds which are absorbed in a few industries and are decentralized in various funds have stronger prediction ability for the market index, i.e. they have strong timing selection ability, but the funds which are dispersed properly in industrial allocation may more concern the stock selection in the industry, and they less predict the market index, and possess weak timing selection ability.

\section{Conclusions}

Through the analysis of the empirical data of the relationship between the fund performance and the concentration on stocks in China, following results can be obtained.

(1) When the risk adjusted return is the index to evaluate the performance of funds, the funds with higher concentration on stocks have good performance, which may comes from the control of risks.

(2) When the risk adjusted return is the index to evaluate the performance of funds, the funds with higher industrial concentration on stocks have good performances. At the same time, the funds with higher industrial concentration on stocks have stronger stock selection ability.

(3) The funds with lower or higher concentration on stocks have weak timing selection ability.

(4) The funds with lower or higher industrial concentration on stocks have strong timing selection ability.

According to above results, when the funds hold centralized stocks, the fund managers have times and energies to carefully study and analyze the stocks which they hold, and they can select the stock portfolio with low risks and high returns to invest, but when the holding stocks are too centralized, the difficulty to adjust the fund position will increase, so the timing selection ability will decrease. But when the holding stocks are centralized in certain industries, the fund managers have times and energies to carefully study and analyze these industries, so they can select the stocks with high incomes and low risks in these industries to invest, and as viewed from the timing selection ability, the funds with proper industrial concentration have weak timing selection ability, that may be because these funds pay more attention to the analysis and comparison of the stocks in various industries, but ignore the prediction and analysis of the whole market, and the funds with lower or higher industrial concentration will have higher timing selection ability because they will expense limited energies to select or analyze the industries. 


\section{References}

Daniel Kent, Mark Grinblatt, Sheridan Titman, and Russ Wermers. (1997). Measuring Mutual Fund Performance with Characteristic-based benchmarks. Journal of Finance. No.52. P.1035-1058.

Fama, Eugene F. and Kenneth R. French. (1996). Multifactor Explanations of Asset Pricing Anomalies. Journal of Finance. No.51. P.55-84.

Hany A. Shawky and David M. Smith. (2005). Optimal Number of Stock Holdings in Mutual Fund Portfolios Based on Market Performance. Finance Review. No.40. P.481-495.

Henriksson and Merton. (1981). On Market Timing and Investment Performance: Statistical Procedure for Evaluating, Forecasts Skills. Journal of Business. No.54. P.513-533.

$\mathrm{Hu}$, Wei \& Zhang, Ming. (2006). Holding-based Valuation on Stock Selection Ability of Funds. Systems EngineeringTheory \& Practice. No.9. P.26-32.

Jensen M. (1968). The performance of mutual funds in the period 1945-64. Journal of Finance. No.23. P.389-416.

Liang, Bin, Chen, Min \& Miu, Baiqi. (2007). Empirical Study on the Relationship Between Holding Concentration and Performance of Close-end Fund. Chinese Journal of Management Science. No.6. P.7-11.

Marcin Kacperczyk, Clemens Sialn, and Lu Zhang. (2005). On the Industry Concentration of Actively Managed Equity Mutual Funds. Journal of Finance. No.60. P.1983-2011.

Sharpe W. F. (1966). Mutual fund performance. Journal of Business. No.39. P.119-138.

Shen, Weitao \& Huang, Xingluan. (2001). Empirical Research and Evaluation of Chinese Security Investment Fund performance. Economic Research. No.9. P.22-30.

Travis Sapp and Xuemin Yan. (2008). Security Concentration and Active Fund Management: Do Focused Funds Offer Superior Performance? Financial Review. No.43. P.27-49.

Treynor and Mazuy. (1966). Can Mutual Funds Outguess the Market. Harvard Business Review. No.44. P.131-136.

Treynor J. (1965). How to rate management investment funds. Harvard Business Review. No.44. P.131-136.

Wang, Cong. (2001). Analysis of the Security Investment Fund Performance Evaluation Model. Economic Research. No.9. P.31-38.

Wu, Chongfeng, Ni, Suyun \& Wong, Yicong. (2002). A Review of the Research on Security Funds Performance Evaluation. Systems Engineering- Theory \& Practice. No.10. P.128-133.

Xie, Hongtao \& Zhou, Shaofu. (2008). Study on the Asset Allocation Concentration Degree and the Investment Performance of Stock Funds. Securities Market Herald. No.5. P.52-56.

Zhang, Xin \& Du, Shuming. (2002). Whether Chinese Security Investment Funds can Win in the Market. Economic Research. No.1. P.1-22.

Table 1. Descriptive statistics of various variables

\begin{tabular}{|c|c|c|c|c|c|c|c|c|c|}
\hline Year & Sample amount & Statistics & $y$ & jensen & vol & ss & tim & $H_{s t k}$ & $H_{\text {ind }}$ \\
\hline \multirow{4}{*}{2004} & \multirow{4}{*}{62} & MIN & 0.33 & -0.0006 & 11.89 & -0.0012 & -1.41 & 0.01 & 0.04 \\
\hline & & MAX & 30.02 & 0.0050 & 18.72 & 0.0055 & 1.01 & 0.10 & 0.66 \\
\hline & & MEAN & 9.82 & 0.0016 & 15.69 & 0.0018 & -0.22 & 0.05 & 0.32 \\
\hline & & STD & 5.73 & 0.0012 & 1.37 & 0.0011 & 0.53 & 0.02 & 0.11 \\
\hline \multirow{4}{*}{2005} & \multirow{4}{*}{76} & MIN & -2.46 & -0.0009 & 11.75 & -0.0016 & -2.31 & 0.01 & 0.17 \\
\hline & & MAX & 22.36 & 0.0039 & 22.52 & 0.0050 & 4.68 & 0.09 & 0.57 \\
\hline & & MEAN & 10.73 & 0.0017 & 15.89 & 0.0010 & 0.85 & 0.04 & 0.28 \\
\hline & & STD & 5.17 & 0.0010 & 1.66 & 0.0011 & 0.99 & 0.02 & 0.09 \\
\hline \multirow{4}{*}{2006} & \multirow{4}{*}{92} & MIN & -22.42 & 0.0000 & 14.50 & 0.0015 & -4.40 & 0.01 & 0.13 \\
\hline & & MAX & 75.11 & 0.0079 & 29.89 & 0.0088 & -0.14 & 0.12 & 0.63 \\
\hline & & MEAN & 20.10 & 0.0035 & 21.18 & 0.0044 & -2.13 & 0.04 & 0.23 \\
\hline & & STD & 18.59 & 0.0014 & 2.97 & 0.0015 & 0.88 & 0.02 & 0.08 \\
\hline \multirow{4}{*}{2007} & \multirow{4}{*}{127} & MIN & 4.14 & 0.0014 & 21.54 & -0.0010 & -2.57 & 0.01 & 0.15 \\
\hline & & MAX & 161.50 & 0.0130 & 34.69 & 0.0125 & 3.52 & 0.11 & 0.61 \\
\hline & & MEAN & 52.98 & 0.0053 & 27.72 & 0.0035 & 1.11 & 0.04 & 0.28 \\
\hline & & STD & 21.90 & 0.0020 & 3.09 & 0.0023 & 0.95 & 0.02 & 0.08 \\
\hline
\end{tabular}


Table 2. Regression result of the formula (7)

\begin{tabular}{|c|l|l|l|l|l|l|}
\hline Performance index (Per) & Intercept & $H_{\text {stk }}$ & $H_{\text {ind }}$ & $D_{1}$ & $D_{2}$ & $D_{3}$ \\
\hline \multirow{2}{*}{$y$} & 9.88 & -1.20 & & 0.90 & 10.28 & 43.16 \\
& $(2.78)$ & $(-0.02)$ & & $(0.29)$ & $(3.46)$ & $(15.26)$ \\
\hline \multirow{2}{*}{ jensen } & 0.001 & $0.009^{*}$ & & 0.000 & 0.002 & 0.004 \\
& $(3.45)$ & $(1.76)$ & & $(0.96)$ & $(7.53)$ & $(14.62)$ \\
\hline \multirow{2}{*}{ vol } & 16.76 & $-16.65^{* *}$ & & -0.12 & 4.89 & 11.15 \\
& $(31.78)$ & $(-2.02)$ & & $(-0.25)$ & $(11.10)$ & $(26.58)$ \\
\hline \multirow{2}{*}{ ss } & 0.001 & 0.008 & & -0.001 & 0.003 & 0.002 \\
& $(3.69)$ & $(1.53)$ & & $(-2.34)$ & $(9.26)$ & $(5.69)$ \\
\hline \multirow{2}{*}{ tim } & -0.34 & 2.51 & & 1.21 & -1.85 & 1.42 \\
& $(-1.80)$ & $(0.86)$ & & $(7.37)$ & $(-11.79)$ & $(9.54)$ \\
\hline \multirow{2}{*}{$y$} & 7.39 & & 7.67 & 1.16 & 10.94 & 43.45 \\
& $(1.83)$ & & $(0.73)$ & $(0.37)$ & $(3.54)$ & $(15.24)$ \\
\hline \multirow{2}{*}{ jensen } & 0.001 & & $0.003^{* * *}$ & 0.000 & 0.002 & 0.004 \\
& $(1.89)$ & & $(2.87)$ & $(1.19)$ & $(7.98)$ & $(14.94)$ \\
\hline \multirow{2}{*}{ vol } & 15.73 & & 0.70 & -0.05 & 5.03 & 11.22 \\
& $(26.05)$ & & $(0.45)$ & $(-0.10)$ & $(10.89)$ & $(26.33)$ \\
\hline \multirow{2}{*}{ ss } & 0.001 & & $0.002^{* *}$ & -0.001 & 0.003 & 0.002 \\
& $(2.29)$ & & $(2.44)$ & $(-2.16)$ & $(9.53)$ & $(5.94)$ \\
\hline \multirow{2}{*}{ tim } & -0.14 & & -0.22 & 1.19 & -1.88 & 1.41 \\
& $(-0.68)$ & & $(-0.40)$ & $(7.25)$ & $(-11.49)$ & $(9.35)$ \\
\hline
\end{tabular}

Note: The values in the brackets are statistics of $t, *, * *$ and $* * *$ respectively denote the significances under the level of $10 \%$, the level of $5 \%$ and the level of $1 \%$. The significance of the regression coefficients of variables about the concentration on stocks is only concerned, and the significances of other variables are not considered here.

Table 3. Regression result of the formula (8)

\begin{tabular}{|c|c|c|c|c|c|c|c|c|}
\hline Performance index (Per) & Intercept & $H_{s t k}$ & $H_{\text {ind }}$ & $D_{1}$ & $D_{2}$ & $D_{3}$ & $H_{s t k}$ & $H_{\text {ind }}$ \\
\hline$y$ & $\begin{array}{l}15.76 \\
(2.59)\end{array}$ & $\begin{array}{l}-239.03 \\
(-1.15)\end{array}$ & $\begin{array}{l}2,179 \\
(1.19)\end{array}$ & & & $\begin{array}{l}0.75 \\
(0.24)\end{array}$ & $\begin{array}{l}9.95 \\
(3.34)\end{array}$ & $\begin{array}{l}42.90 \\
(15.14)\end{array}$ \\
\hline jensen & $\begin{array}{l}0.001 \\
(1.18) \\
\end{array}$ & $\begin{array}{l}0.027 \\
(1.46) \\
\end{array}$ & $\begin{array}{l}-0.167 \\
(-1.03) \\
\end{array}$ & & & $\begin{array}{l}0.000 \\
(1.00) \\
\end{array}$ & $\begin{array}{l}0.002 \\
(7.59) \\
\end{array}$ & $\begin{array}{l}0.004 \\
(14.66) \\
\end{array}$ \\
\hline vol & $\begin{array}{l}16.97 \\
(18.76) \\
\end{array}$ & $\begin{array}{l}-25.29 \\
(-0.82) \\
\end{array}$ & $\begin{array}{l}79.18 \\
(0.29) \\
\end{array}$ & & & $\begin{array}{l}-0.12 \\
(-0.26) \\
\end{array}$ & $\begin{array}{l}4.88 \\
(11.01) \\
\end{array}$ & $\begin{array}{l}11.14 \\
(26.44) \\
\end{array}$ \\
\hline ss & $\begin{array}{l}0.002 \\
(2.92)\end{array}$ & $\begin{array}{l}-0.010 \\
(-0.50) \\
\end{array}$ & $\begin{array}{l}0.168 \\
(0.94)\end{array}$ & & & $\begin{array}{l}-0.001 \\
(-2.38) \\
\end{array}$ & $\begin{array}{l}0.003 \\
(9.14)\end{array}$ & $\begin{array}{l}0.002 \\
(5.60)\end{array}$ \\
\hline tim & \begin{tabular}{|l|}
-0.86 \\
$(-2.68)$ \\
\end{tabular} & $\begin{array}{l}23.55^{* *} \\
(2.16)\end{array}$ & $\begin{array}{l}-192 * * \\
(-2.01)\end{array}$ & & & $\begin{array}{l}1.22 \\
(7.49)\end{array}$ & $\begin{array}{l}-1.82 \\
(-11.6) \\
\end{array}$ & $\begin{array}{l}1.45 \\
(9.72)\end{array}$ \\
\hline$y$ & $\begin{array}{l}6.63 \\
(0.86) \\
\end{array}$ & & & $\begin{array}{l}12.85 \\
(0.28)\end{array}$ & $\begin{array}{l}-7.78 \\
(-0.12) \\
\end{array}$ & $\begin{array}{l}1.14 \\
(0.36)\end{array}$ & $\begin{array}{l}10.98 \\
(3.53)\end{array}$ & $\begin{array}{l}43.43 \\
(15.18) \\
\end{array}$ \\
\hline jensen & $\begin{array}{l}0.001 \\
(0.86) \\
\end{array}$ & & & $\begin{array}{l}0.003 \\
(0.81) \\
\end{array}$ & $\begin{array}{l}-0.001 \\
(-0.16) \\
\end{array}$ & $\begin{array}{l}0.000 \\
(1.18)\end{array}$ & $\begin{array}{l}0.002 \\
(7.94) \\
\end{array}$ & $\begin{array}{l}0.004 \\
(14.88) \\
\end{array}$ \\
\hline vol & $\begin{array}{l}15.38 \\
(13.40) \\
\end{array}$ & & & $\begin{array}{l}.04 \\
(0.45) \\
\end{array}$ & $\begin{array}{l}-3.51 \\
(-0.35) \\
\end{array}$ & $\begin{array}{l}-0.05 \\
(-0.11) \\
\end{array}$ & $\begin{array}{l}5.05 \\
(10.85) \\
\end{array}$ & $\begin{array}{l}1.21 \\
(26.20) \\
\end{array}$ \\
\hline ss & $\begin{array}{l}0.000 \\
(0.11)\end{array}$ & & & $\begin{array}{l}0.008^{*} \\
(1.82)\end{array}$ & $\begin{array}{l}-0.008 \\
(-1.3) \\
\end{array}$ & $\begin{array}{l}-0.001 \\
(-2.2) \\
\end{array}$ & $\begin{array}{l}0.003 \\
(9.62)\end{array}$ & $\begin{array}{l}0.002 \\
(5.85)\end{array}$ \\
\hline tim & $\begin{array}{l}0.77 \\
(1.92)\end{array}$ & & & $\begin{array}{l}-6.43 * * * \\
(-2.7)\end{array}$ & $\begin{array}{l}9.33 * * * \\
(2.68)\end{array}$ & $\begin{array}{l}1.21 \\
(7.44) \\
\end{array}$ & $\begin{array}{l}-1.92 \\
(-11)\end{array}$ & $\begin{array}{l}1.44 \\
(9.61)\end{array}$ \\
\hline
\end{tabular}

Note: The values in the brackets are statistics of $t, *, * *$ and $* * *$ respectively denote the significances under the level of $10 \%$, the level of $5 \%$ and the level of $1 \%$. The significance of the regression coefficients of variables about the concentration on stocks is only concerned, and the significances of other variables are not considered here. 